\title{
Herpes zoster na adolescência: caso clínico
}

\section{Herpes zoster in adolescence: A clinical case \\ Herpes zóster en la adolescencia: caso clínico}

Aline Salmito Frota. Universidade Federal do Ceará (UFC). Fortaleza, CE, Brasil. alinesalmito@ hotmail.com. (Autora correspondente)

Verônica Riquet de Siqueira Lima. Universidade Federal do Ceará (UFC). Fortaleza, CE, Brasil. veronicariquet@yahoo.com.br

Hercilia Maria Carvalho Queiroz. Universidade Federal do Ceará (UFC). Fortaleza, CE, Brasil. herciliaqueiroz@ hotmail.com

Israel Leitão Maia. Universidade Federal do Ceará (UFC). Fortaleza, CE, Brasil. israeldermato@gmail.com

José Wilson Accioly Filho. Universidade Federal do Ceará (UFC). Fortaleza, CE, Brasil. josewilsonaccioly@yahoo.com.br

Márcia Gonçalves Brasil. Universidade Federal do Ceará (UFC). Fortaleza, CE, Brasil. marciavmc@terra.com.br

Maria Genúcia Cunha Matos. Universidade Federal do Ceará (UFC). Fortaleza, CE, Brasil. genucia@gmail.com

\section{Resumo}

Varicela e herpes zoster (HZ) são entidades clínicas distintas causadas pelo vírus varicela-zoster (VZV). Varicela é uma doença aguda, altamente contagiosa, ocorrendo mais frequentemente na infância como resultado de infecção primária em indivíduo susceptível. $\mathrm{HZ}$ caracteriza-se por dor unilateral e aparecimento de vesículas sobre base eritematosa seguindo o território de um dermátomo, respeitando a linha mediana, ocorrendo anos após o primeiro contato com o VZV. Os principais fatores de risco para $\mathrm{HZ}$ são idade elevada e disfunção celular imune. Apresenta-se aqui caso extenso de herpes zoster em indivíduo imunocompetente, com localização atípica e faixa etária pouco comum. O caso apresentado chamou atenção pela extensão do acometimento da lesão e por ocorrer em um paciente imunocompetente e em faixa etária incomum.

\section{Abstract}

Varicella and herpes zoster $(\mathrm{HZ})$ are distinct clinical entities caused by the varicella-zoster virus $(\mathrm{VZV})$. Varicella is an acute, highly contagious disease that occurs most commonly in childhood as a result of a primary infection in a susceptible individual. $\mathrm{HZ}$ occurs years after the first contact with VZV and is characterized by unilateral pain and appearance of vesicles on an erythematous base following the territory of a dermatome, respecting the midline. The main risk factors for $\mathrm{HZ}$ are high age and cellular immune dysfunction. We present a case of herpes zoster with extensive and lush lesions, in an immunocompetent individual, with atypical location and uncommon age. The case drew attention by the extent of involvement of the injury, immunocompetent individual and in unusual age.

\section{Resumen}

La varicela y el herpes zoster $(\mathrm{HZ})$ son distintas entidades clínicas causadas por el virus de la varicela-zoster (VZV). La varicela es una enfermedad aguda, altamente contagiosa, que se produce con más frecuencia en la infancia, como resultado de una infección primaria en individuos susceptibles. El HZ se caracteriza por el dolor unilateral y aparición de vesículas sobre una base eritematosa siguiendo el territorio de un dermatomo, respetando la línea media, que se produce años después del primer contacto con VZV. Los principales factores de riesgo para $\mathrm{HZ}$ son la elevada edad y la disfunción inmune celular. Se presenta aquí un caso de herpes zoster en individuo imunocompetente, con ubicación atípica y edad poco común. El caso llamó la atención por el grado de la lesión y por producirse en paciente imunocompetente y en edad inusual.

Como citar: Frota AS, Lima VRS, Queiroz HMC, Maia IL, Accioly Filho JW, Brasil MG, Matos MGC. Herpes zoster na adolescência: caso clínico. Rev Bras Med Fam Comunidade. 2015;10(36)1-7. http://dx.doi.org/10.5712/rbmfc10(36)704
Palavras-chave: Herpes Zoster Herpesvirus Humano 3 Varicela

\section{Keywords:}

Herpes Zoster Herpesvirus 3, Human Varicella

\section{Palabras clave:} Herpes Zóster Herpesvirus Humano 3 Varicela

\section{Fonte de financiamento:} declaram não haver.

Parecer CEP: 027.04.13 (HUWC), aprovado em 26/04/2013

Conflito de interesses: declaram não haver. Procedência e revisão por pares: revisado por pares. Recebido em: 16/02/2013. Aprovado em: 25/04/2015. 


\section{Introdução}

Varicela e herpes zoster $(\mathrm{HZ})$ são entidades clínicas distintas causadas pelo vírus varicela-zoster (VZV). ${ }^{1,2}$ Varicela é uma doença aguda, altamente contagiosa, que ocorre mais frequentemente na infância, sendo resultado de uma infecção primária em indivíduo susceptível. ${ }^{2,3} \mathrm{HZ}$ é caracterizado por dor unilateral e aparecimento de vesículas sobre base eritematosa, seguindo o território de um dermátomo (distribuição dermatômica), respeitando a linha mediana e ocorre como resultado de reativação endógena do VZV, que persistiu na forma latente num gânglio sensorial após um episódio de varicela, ${ }^{2-5}$ podendo ocorrer também após vacina para varicela (apesar de ser menos comum) visto que trata-se de vacina de vírus atenuado. ${ }^{6,7}$ Um dos principais fatores de risco para $\mathrm{HZ}$ é a idade, com sua incidência aumentando em pessoas com mais de 60 anos e/ou em pessoas com disfunção celular imune. .,4,8 $^{3}$ Outros fatores relacionados, porém sem confirmação, são: sexo feminino, trauma físico no dermátomo afetado e raça negra. A exposição ao VZV intraútero ou durante os primeiros meses de vida é um dos principais fatores para o desenvolvimento de herpes zoster em crianças saudáveis. ${ }^{5} \mathrm{~A}$ ocorrência de herpes zoster pós-natal é menos comum que pós-infecções intrauterinas, 30\% contra $69 \%$, respectivamente. ${ }^{9}$ Apresenta-se aqui um caso de herpes zoster em faixa etária pediátrica, em indivíduo imunocompetente, que torna-se ainda mais incomum pela apresentação exuberante e localização atípica.

\section{Detalhamento do Caso}

Adolescente, 13 anos de idade, sexo masculino, atendido em Unidade de Atenção Terciária, proveniente de Serviço de Atenção Primária, com história de inúmeras vesículas em região genital e nádega esquerda havia cerca de três dias, respeitando a linha média, associado à disúria e dor intensa no local. A mãe referia febre havia dois dias. Negava patologias prévias, inclusive varicela. Apresentava calendário vacinal em dia, porém não havia tomado vacina contra varicela, já que esta não consta no calendário do Ministério da Saúde. Negava viagens recentes, alergias, uso de drogas imunossupressoras e história familiar para qualquer doença imunossupressora. Estava em uso de Cefalexina há um dia e compressas de permanganato de potássio, pois apresentara infecção cutânea secundária em alguns locais. Ao exame físico, apresentava múltiplas vesículas agrupadas sobre base eritematosa em corpo do pênis, glande, saco escrotal, nádega e raiz da coxa esquerda, tendendo a respeitar linha média, seguindo dermátomo (território de S2/S3, Figuras 1-3).

Foi prescrito Aciclovir $800 \mathrm{mg}$ por dose, cinco vezes ao dia por sete dias, manteve-se a Cefalexina pelo mesmo período e foram solicitados exames, incluindo citologia de Tzanck (Figura 4). Paciente retornou para consulta em uma semana, apresentando melhora considerável do quadro, que estava em involução, com várias lesões crostosas e ausência de febre (Figura 5). Os resultados dos exames laboratoriais, como hemograma completo, função renal e hepática, sorologias para sífilis e HIV, 1 e 2 vieram sem alterações.

\section{Discussão}

$\mathrm{HZ}$ é mais prevalente em pessoas mais velhas, devido a um declínio em sua resposta celular imune, ${ }^{6}$ assim como em indivíduos com doenças sistêmicas, particularmente com imunodepressão. ${ }^{3,4} \mathrm{O}$ caso apresentado chamou atenção pela extensão do acometimento da lesão e por ocorrer em um menino, imunocompetente, em faixa etária incomum e localização atípica. Um estudo realizado pela Faculdade 


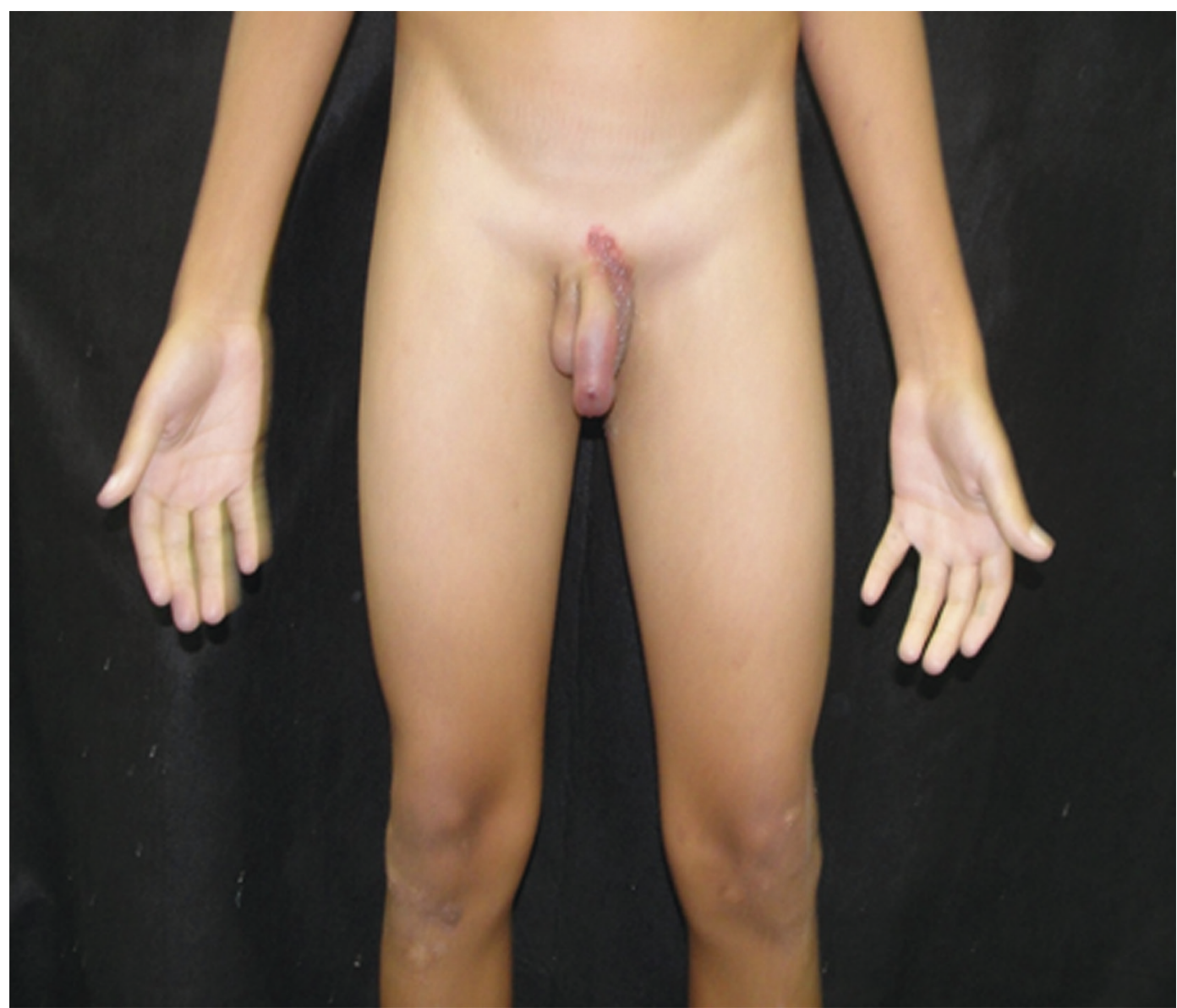

Figura 1. Foto mostrando agrupamento de vesículas em genitália, respeitando linha média.

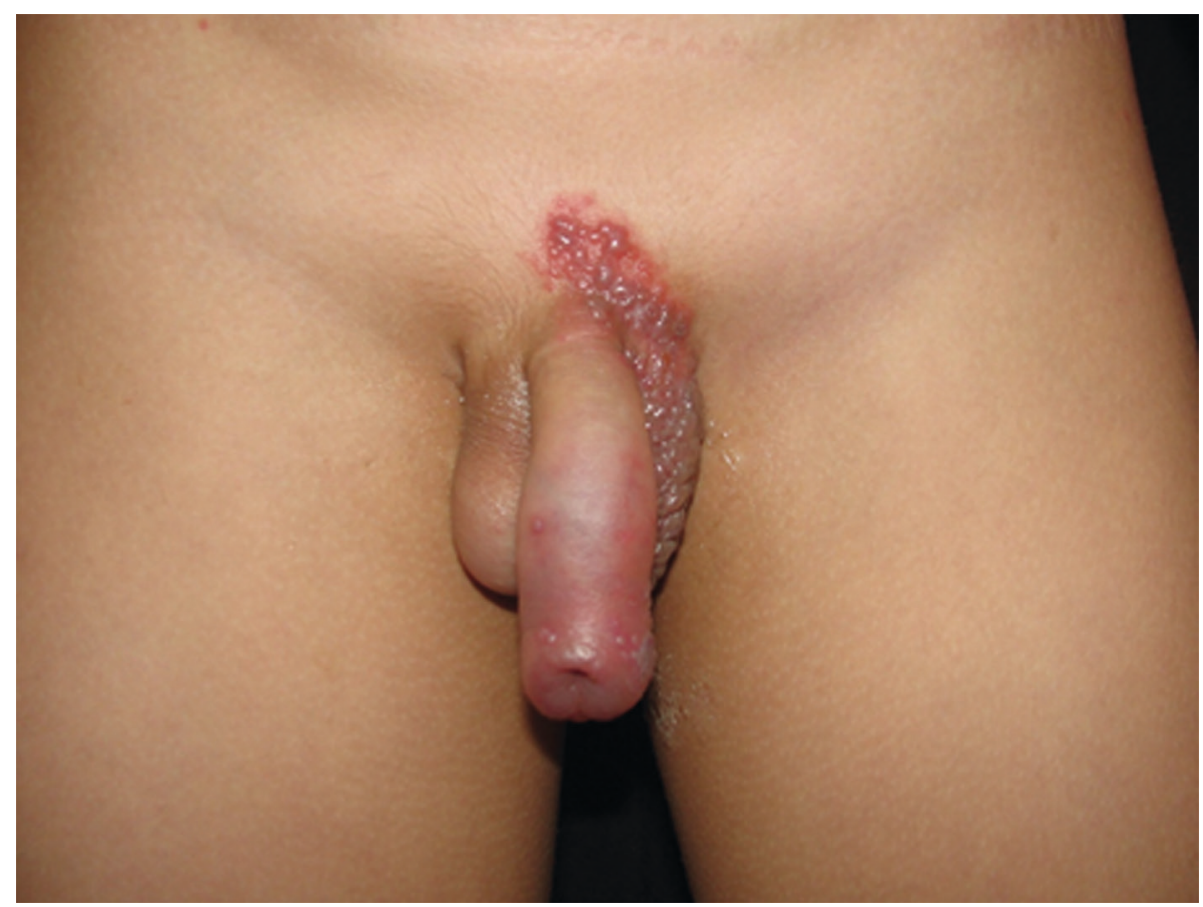

Figura 2. Imagem aproximada da lesão. 


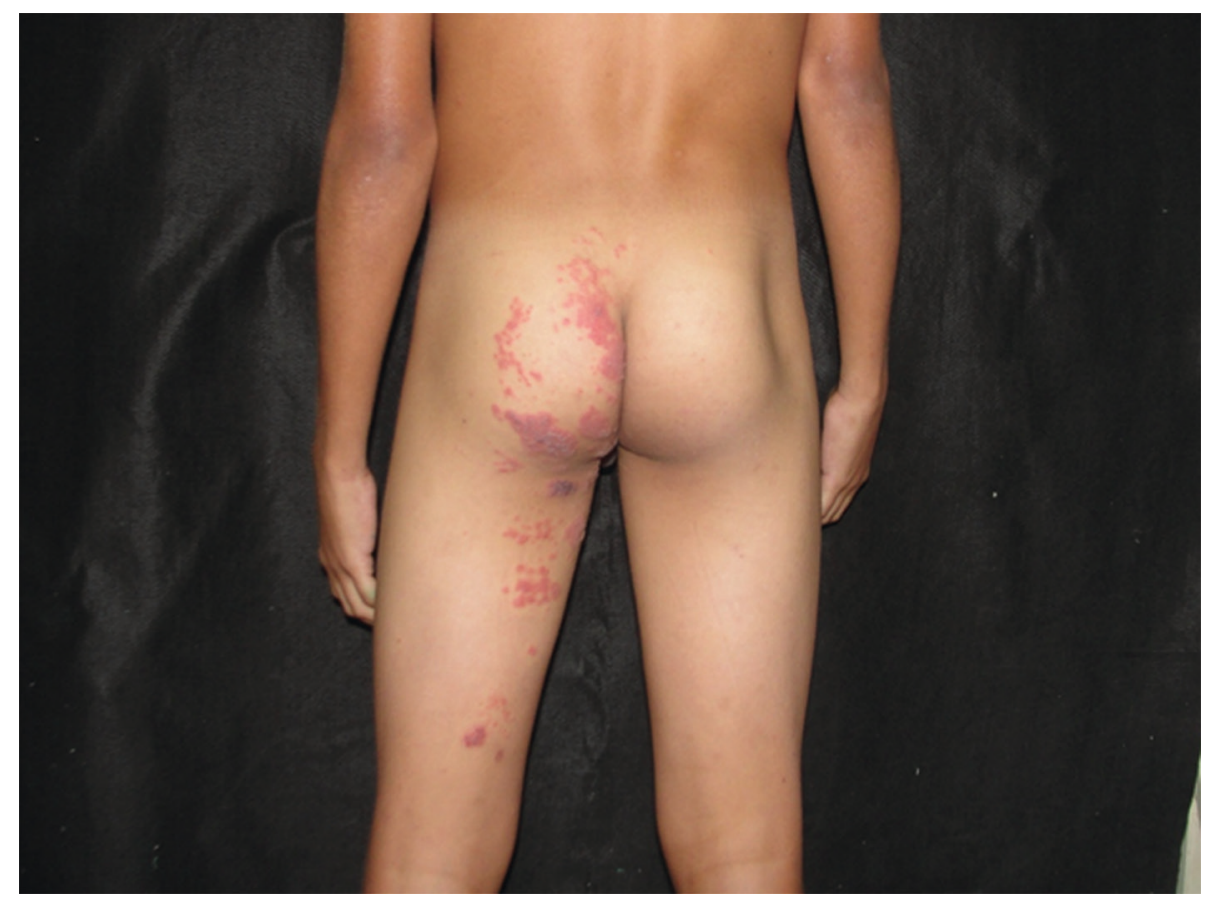

Figura 3. Vesículas acometendo grande área de nádega e coxa esquerda.

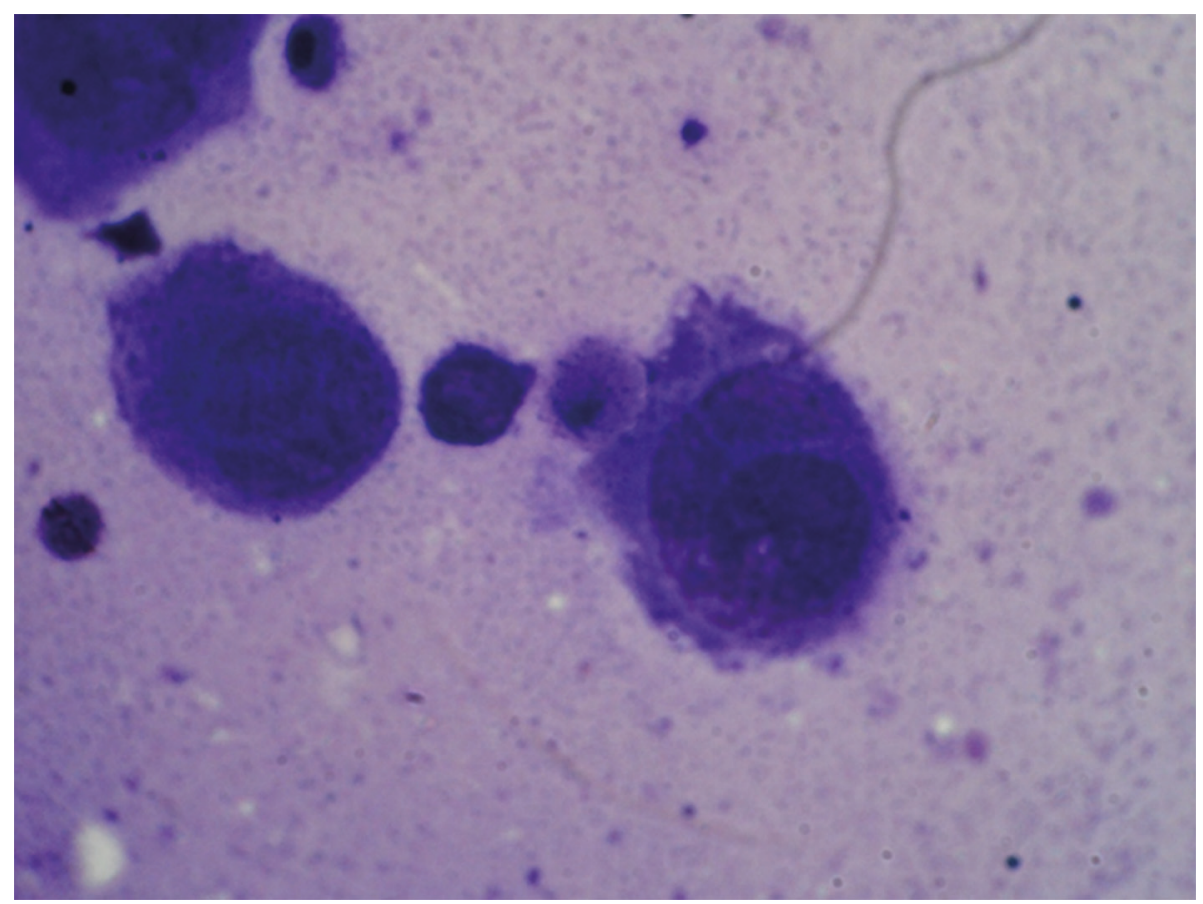

Figura 4. Citologia de Tzanck positiva, mostrando células gigantes multinucleadas.

de Medicina da Universidade de São Paulo, em 1990, que avaliou 469 casos de HZ, questionou se o HZ seria mais comum entre jovens do que entre idosos, uma vez que, segundo dados da literatura mundial, além de não haver caráter sazonal na infecção nem predominância quanto a sexo ou raça, a incidência aumentaria proporcionalmente com a idade, sendo pouco frequente em crianças e adolescentes, e pacientes imunodeprimidos seriam mais susceptíveis. 


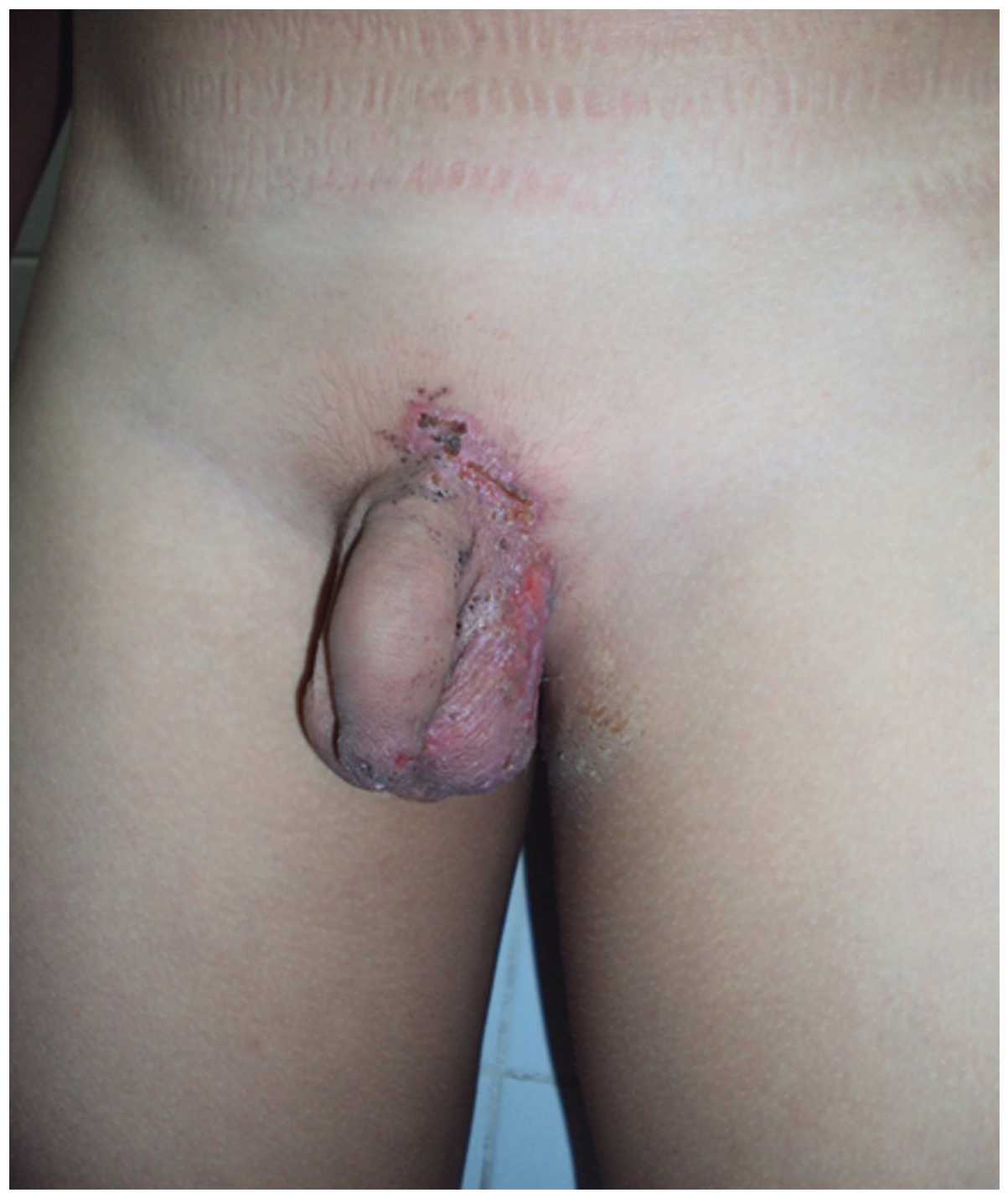

Figura 5. Aspecto das lesões após uma semana de tratamento com Aciclovir.

Porém, no estudo em questão, foi visto que 38\% dos casos foram registrados em jovens ( 0 a 29 anos) enquanto apenas $24,1 \%$ foram registrados entre idosos (60 anos ou mais), mostrando uma distribuição bimodal e alertando para o uso de dados estrangeiros em nossa realidade, com a justificativa de que isso poderia levar a comunidade médica e científica a incorrer em erros, como supor que paciente jovem e saudável que apresente $\mathrm{HZ}$ poderia estar sofrendo de algum processo sistêmico grave. ${ }^{10}$ Outro estudo retrospectivo, realizado em uma cidade norte-americana, que avaliou 173 casos de $\mathrm{HZ}$ em pessoas com menos de 20 anos de idade, mostrou que, dos 135 casos cujo local acometido estava descrito no prontuário, $65 \%$ ocorreu em região torácica, seguido de região cervical, lombar, nervo craniano e somente $4 \%$ mostrou acometimento sacral. ${ }^{11}$

O diagnóstico é essencialmente clínico, com um quadro característico. ${ }^{1,6}$ No caso em questão, foram solicitados exames para verificar se o mesmo teria alguma doença imunossupressora de base, porém, como citado anteriormente, esta investigação adicional é desnecessária se não existirem outros achados que corroborem a suspeita clínica. Pode-se fazer isolamento do vírus em cultura de células inoculadas, 
além de estudo histopatológico e citodiagnóstico, e o diagnóstico definitivo é dado por isolamento do vírus em cultura de células inoculadas. ${ }^{2,5,12,13}$ Em crianças, a doença é menos grave, a neuralgia pós-herpética raramente ocorre e o tratamento com Aciclovir, que é aprovado para o tratamento em crianças (Famciclovir e Valaciclovir não são), ${ }^{8}$ pode ser desnecessário. ${ }^{5,6,8}$ Porém, o tratamento com antiviral é seguro, efetivo ${ }^{6}$ e pode ser recomendado em todos os casos de $\mathrm{HZ}$, devendo-se iniciar em até 72 horas do início do quadro. ${ }^{13,14}$ Preconiza-se Aciclovir via oral para adultos saudáveis com $\mathrm{HZ}$ na dose de $20 \mathrm{mg} / \mathrm{Kg} / \mathrm{dose}$ (máximo de $800 \mathrm{mg} /$ dose) em quatro a cinco doses ao dia por cinco a sete dias. ${ }^{12,14} \mathrm{~A}$ maioria dos estudos não recomenda o uso de Aciclovir em herpes zoster não complicado em crianças, porém, alguns autores recomendam. ${ }^{6,15}$ Como profilaxia, há uma vacina disponível, utilizando a mesma cepa de VZV atenuada, com uma concentração maior, fazendo-se dose única de $0,65 \mathrm{ml}$ em maiores de 60 anos de idade. ${ }^{12}$

Portanto, o herpes zoster pode acometer crianças e adolescentes saudáveis e, nestes casos, se houver anamnese e exame físico sem alterações, uma investigação adicional para imunodeficiência e malignidade não é necessária, ${ }^{8}$ dado que tranquiliza, uma vez que a tendência dos médicos, de maneira geral, é achar que deve ser feita uma investigação para doenças, principalmente as que cursam com imunodepressão.

\section{Referências}

1. Bozko MP, Favaretto SL, Ponzio HA. Infecções pelo Herpesvírus e pelo Vírus Varicela Zoster. In: Duncan BB, Schmidt MI, Giugliani EJR, Duncan MS, Giugliani C, eds. Medicina Ambulatorial. Condutas de atenção primária baseadas em evidências. 3a ed. Porto alegre: Artmed; 2004, p.1020-3.

2. Sampaio SAP, Rivitti EA. Dermatoses por vírus. In: Sampaio SAP, Rivitti EA, eds. Dermatologia. São Paulo: Artes Médicas; 2007. p.558-61.

3. Civen R, Chaves SS, Jumaan A, Wu H, Mascola L, Gargiullo P, et al. The incidence and clinical characteristics of herpes zoster among children and adolescents after implementation of varicella vaccination. Pediatr Infect Dis J. 2009;28(11):954-9. DOI:http://dx.doi.org/10.1097/INF.0b013e3181a90b16

4. Salleras M, Domínguez A, Soldevila N, Prat A, Garrido P, Torner N, et al. Contacts with children and young people and adult risk of suffering herpes zoster. Vaccine. 2011;29(44):7602-5. DOI: http://dx.doi.org/10.1016/j.vaccine.2011.08.023

5. Rodríguez-Fanjul X, Noguera A, Vicente A, González-Enseñat MA, Jiménez R, Fortuny C. Herpes zoster in healthy infants and toddlers after perinatal exposure to varicella-zoster virus: a case series and review of the literature. Pediatr Infect Dis J. 2010;29(6):574-6.

6. Wan KS, Su YM. Herpes zoster in a 13-year-old healthy immunocompetent female patient. Med Mal Infect. 2011;41(3): 156-7. DOI:http://dx.doi.org/10.1016/j.medmal.2010.09.017

7. Uebe B, Sauerbrei A, Burdach S, Horneff G. Herpes zoster by reactivated vaccine varicella zoster virus in a healthy child. Eur J Pediatr. 2002;161(8):442-4. DOI: http://dx.doi.org/10.1007/s00431-002-0981-1

8. Feder HM Jr, Hoss DM. Herpes zoster in otherwise healthy children. Pediatr Infect Dis J. 2004;23(5):451-7. DOI:http:// dx.doi.org/10.1097/01.inf.0000126901.88982.32

9. Kurlan JG, Connelly BL, Lucky AW. Herpes zoster in the first year of life following postnatal exposure to varicella-zoster virus: four case reports and a review of infantile herpes zoster. Arch Dermatol. 2004;140(10):1268-72. DOI: http://dx.doi. org/10.1001/archderm.140.10.1268

10. Castro L, Shen S. Zoster: mais frequente entre jovens que entre idosos. An Bras Dermatol. 1990;65(3):129-33.

11. Guess HA, Broughton DD, Melton LJ 3rd, Kurland LT. Epidemiology of herpes zoster in children and adolescents: a population-based study. Pediatrics. 1985;76(4):512-7. PMID: 3863086 
12. Guedes ACM, Avelleira JCR, Lupi O, Abraham LS, Azulay DR, Azulay-Abulafia L. Doenças virais de interesse dermatológico. In: Azulay DR, Azulay RD, Azulay-Abulafia L. Dermatologia. Rio de Janeiro: Guanabara-Koogan; 2011. p.304-18.

13. Straus SE, Oxman MN, Schmader FE. Varicella and Herpes Zoster. In:Wolff K, Goldsmith LA, eds. Fitzpatrick's Dermatology in General Medicine. 7th ed. New York: McGraw-Hill Medical; 2008. p.1885-98.

14. Whitley RJ. Therapy of herpes virus infections in children. Adv Exp Med Biol. 2008;609:216-32. PMID: 18193668

15. Smith CG, Glaser DA. Herpes zoster in childhood: case report and review of the literature. Pediatr Dermatol. 1996;13(3): 226-9. PMID:8806124 DOI: http://dx.doi.org/10.1111/j.1525-1470.1996.tb01208.x 